\title{
WHAT IS NEW REGARDING THE TREATMENT OF DYSLIPIDEMIA IN THE 2019 EUROPEAN SOCIETY OF CARDIOLOGY GUIDELINES?
}

\author{
Madalina A. MUNTEANU ${ }^{1}$, Gina GHEORGHE ${ }^{1}$, Ana Maria A. STANESCU ${ }^{1}$, Ovidiu G. BRATU1,2, \\ Camelia C. DIACONU ${ }^{1,3 凶}$ \\ ${ }^{1}$ University of Medicine and Pharmacy „Carol Davila“, Bucharest, Romania \\ ${ }^{2}$ University Emergency Central Military Hospital, Academy of Romanian Scientists, Bucharest, Romania \\ ${ }^{3}$ Clinical Emergency Hospital of Bucharest, Romania
}

Received 28 Sept 2019, Accepted 01 Nov 2019

https://doi.org/10.31688/ABMU.2019.54.4.21

\begin{abstract}
Despite considerable improvements in medical care over the past 25 years, cardiovascular disease (CVD) remains a major public health challenge. Dyslipidemias are one of the topics of greatest interest in cardiology. Decreasing serum cholesterol level is a central objective for preventing cardiovascular events. The current European Society of Cardiology guidelines recommend evaluation of the cardiovascular risk, treatment decisions being based on this risk, and clinician-patient discussion about the risk (shared decision making).
\end{abstract}

Keywords: atherosclerosis, cardiovascular risk, dyslipidemia, LDL-cholesterol, triglycerides.

\section{Résumé}

Qu'est-ce qu'il y a de neuf dans le traitement de la dyslipidémie dans le guide de la Société Européenne de Cardiologie pour l'année 2019?

Malgré l'amélioration considérable des soins médicaux pendant les 25 dernières années, les maladies cardiovasculaires $(\mathrm{MCV})$ restent un défi majeur pour la santé publique. Les dyslipidémies sont l'un des sujets de plus grand intérêt en cardiologie. La diminution du taux de cholestérol sérique est un objectif central dans la prévention des événements cardiovasculaires. Les directives actuelles de la Société Européenne de Cardiologie recommandent l'évaluation du risque cardiovasculaire, les décisions de traitement en fonction de ce risque et la discussion entre le clinicien et le patient sur le risque (prise de décision partagée).

Mots-clés: athérosclérose, risque cardiovasculaire, dyslipidémie, cholestérol LDL, triglycérides. 


\section{INTRODUCTION}

In August 2019, the European Society of Cardiology (ESC) and European Atherosclerosis Society (EAS) released updates to their 2016 guidelines for the management of dyslipidemia ${ }^{1,2}$. Cardiovascular diseases are still the leading cause of death in Europe, accounting for $47 \%$ of all premature deaths, before the age of 65 years old ${ }^{3}$.

Dyslipidemia is a modifiable major risk factor that plays a significant role in the development of atherosclerotic cardiovascular disease. Nowadays, more patients are surviving their first cardiovascular (CV) event and are at high-risk of recurrences. Prevention is defined as a co-ordinated set of actions, either at the population or individual level, aimed at eliminating or minimizing the impact of CV diseases and their related disabilities. People of all ages should be encouraged to sustain and adopt a healthy lifestyle, especially those with established ASCVD (Atherosclerotic Cardiovascular Disease) ${ }^{1}$.

\section{Cardiovascular risk categories}

All current guidelines on the prevention of ASCVD in clinical practice recommend the assessment of total cardiovascular disease (CVD) risk. To establish the importance of dyslipidemias as a cardiovascular risk factor, the European Society of Cardiology guideline resumes the overall assessment of cardiovascular risk. There are many models, but since 2003, the ESC has adopted the SCORE (Systematic Coronary Risk Estimation) risk table, based on five main risk factors: sex, age, smoking, blood pressure values and total cholesterol values. Depending on the presence and values of these parameters, the risk of cardiovascular death in the following ten years is estimated. SCORE estimation system can assist in making logical therapeutic management decisions. In the new ESC guideline, SCORE risk table has been extended to older people. These guidelines include illustrative charts for older people. Calibrated country-specific versions are available for many European countries and can be found at http://www.heartscore.org ${ }^{1,4}$.

The recommendations of the new guideline are the following:

- For very high-risk patients (10-year risk of CV death $>10 \%$ ) an LDL cholesterol (LDL-C) reduction of at least $50 \%$ from baseline and an LDL-C goal of less than $1.4 \mathrm{mmol} / \mathrm{L}(<55 \mathrm{mg} / \mathrm{dL})$ are recommended ${ }^{1}$.

- For very high-risk patients who experience a second cardiovascular event within 2 years (not necessarily of the same type as the first event) while being under treatment with a maximally tolerated statin therapy, an LDL-C goal of less than $1.0 \mathrm{mmol} / \mathrm{L}$ ( $<40 \mathrm{mg} / \mathrm{dL}$ ) may be considered ${ }^{1}$.

- For patients at high risk (10-year risk for $\mathrm{CV}$ death of $5 \%$ to $10 \%$ ), an LDL-C reduction of $50 \%$ or greater from baseline and an LDL-C goal of less than $1.8 \mathrm{mmol} / \mathrm{L}(<70 \mathrm{mg} / \mathrm{dL})$ may be considered ${ }^{1}$.

- For individuals at moderate risk (10-year risk for CV death of $1 \%$ to $5 \%$ ), an LDL-C goal of less than $2.6 \mathrm{mmol} / \mathrm{L}(<100 \mathrm{mg} / \mathrm{dL})$ should be considered ${ }^{1}$.

- For individuals at low risk (10-year risk for CV death <1\%), an LDL-C goal of less than $3.0 \mathrm{mmol} / \mathrm{L}(<116 \mathrm{mg} / \mathrm{dL})$ may be considered ${ }^{1}$.

\section{New recommendations in the 2019 guidelines, compared to the 2016 version}

Revisions have been made to the risk stratification categories so that patients with ASCVD (previous acute coronary syndrome (ACS), stable angina, coronary revascularization, stroke and transient ischemic attack, peripheral arterial disease), diabetes with target organ damage or having at least 3 major risk factors or long duration over 20 years of type 1 diabetes mellitus), familial hypercholesterolemia and severe chronic kidney disease (eGFR $<30 \mathrm{~mL} / \mathrm{min}$ ) are all included into a very high risk ${ }^{4}$ category. Also, ACS patients are now considered to be at very high-risk of recurrent events.

Assessment of arterial (carotid and/or femoral) plaque burden by arterial ultrasonography and coronary artery calcium (CAC) score assessment with computed tomography (CT) should be considered as a risk modifier in individuals at low to moderate risk $^{1}$. A recent meta-analysis from the US Preventive Services Task Force summarized the available evidence on the value of non-traditional risk factors for risk prediction ${ }^{5}$. Also, a 6 year follow up of the prospective multicenter International CONFIRM long-term study demonstrated that coronary computed tomographic angiography improved prognostication of 6-year all-cause mortality beyond a set of conventional risk factors (RF) alone ${ }^{6}$.

Considering new insights from epidemiological and Mendelian randomization studies that Lipoprotein(a) ( $\mathrm{Lp}(\mathrm{a}))$ is causal in ischemic heart disease, the guidelines now recommend measurement of $\mathrm{Lp}(\mathrm{a})$ at least once in adults. Randomized placebo-controlled trials of $\mathrm{Lp}(\mathrm{a})$ reduction in individuals with very high concentrations, in order to reduce cardiovascular disease are awaited and also recent genetic evidence has shown that elevated Lp(a) is a cause of aortic valve stenosis, myocardial infarction and atherosclerotic arterial stenosis? ${ }^{7}$. In the randomized HPS2-THRIVE trial of niacin-laropiprant versus placebo, on a background of simvastatin therapy, the authors have concluded that novel therapies that reduce 
high Lp(a) levels by at least $80 \mathrm{nmol} / \mathrm{L}(\approx 40 \%)$ may be needed to produce worthwhile benefits in people at the highest risk because of $\mathrm{Lp}(\mathrm{a})^{8}$. Current options for treatment of high $\mathrm{Lp}(\mathrm{a})$ are limited to the Proprotein convertase subtilisin/kexin type 9 (PCSK9) inhibitors, which have been shown to reduce the levels by $25-30 \%$ on average, with or without background statin therapy ${ }^{1,9,10}$. Patients treated with PCSK9 in a study from Denmark do not resemble the populations from the major endpoint studies, as the majority of this real-life population is statin intolerant. The authors concluded an overall reduction of LDL-c of approximately $50 \%$, even though the number of patients reaching their treatment target remains low $^{11}$.

The guidelines emphasize the importance of combination therapy, first with ezetimibe, followed by a PCSK9 inhibitor, to achieve the recommended targets in high-risk patients ${ }^{1}$. In the IMPROVE-IT trial, the addition of ezetimibe to simvastatin therapy provided an additional benefit to post ACS-patients. When added to statin therapy, ezetimibe resulted in incremental lowering of LDL-cholesterol levels ${ }^{1,12}$.

Statin treatment remains the first choice for managing high triglycerides $(\mathrm{TG})(>200 \mathrm{mg} / \mathrm{dL}$ or $2.3 \mathrm{mmol} / \mathrm{L}$ ). The new guidelines have taken account of evidence from REDUCE-IT and recommend $n-3$ polyunsaturated fatty acids (PUFAs) (particularly icosapent ethyl $2 \times 2 \mathrm{~g}$ daily) in high-risk patients with persistently elevated TG (between $135-499 \mathrm{mg} / \mathrm{dL}$ or 1.5 and $5.6 \mathrm{mmol} / \mathrm{L}$ ) despite statin treatment ${ }^{1,13}$. Omega-3 fatty acids like eicosapentaenoic acid (EPA) only in a pharmacologic dose reduce fasting TG and interfere with mechanisms of atherosclerosis that result in reduced cardiovascular events ${ }^{14}$. In high-risk patients, at LDL-c goal but with TG $>200 \mathrm{mg} / \mathrm{dL}$ or $>2.3 \mathrm{mmol} / \mathrm{L}$, fenofibrate or bezafibrate may be considered in combination with statins ${ }^{1,15-18}$.

Cardiovascular disease is the most important cause of mortality and morbidity in elderly people worldwide. In the ESC guidelines, in people aged $\leq 75$ years, treatment with statins is recommended for primary prevention, according to the level of risk ${ }^{1}$. The evidence for statin therapy is more limited in patients over 75 years old, though is still consistent with a benefit. The new guidelines advise the estimation of the level of risk, health status, baseline LDL-c and the risk of drug interactions when deciding whether statins are appropriate in patients aged 75 years or more $^{1,19}$.

Statin therapy is not recommended in pre-menopausal women with DM who are considering pregnancy or do not use adequate contraception ${ }^{1}$. Statins are not indicated during pregnancy due to teratogenic effects on fetal development and should be avoided in all women who are planning pregnancy ${ }^{1,20}$.

\section{Conclusions}

In conclusion, the new 2019 ESC/EAS dyslipidemia guidelines draw attention to the LDL-c levels that should be lowered as much as possible to prevent cardiovascular disease. There is no lower limit of LDL-c that is known to be unsafe. The absolute LDL-c reduction drives the clinical benefit. The guidelines focused on a new way of stratifying risk, new revised concepts, more intensive goals for the high-risk population and an increased focus on combination therapy. Also, guidelines recommend that the patient should be included in decisions on cardiovascular risk management (shared decision making).

\section{Compliance with Ethics Requirements:}

„The authors declare no conflict of interest regarding this article"

\section{References}

1. Mach F, Baigent C, Catapano AL, et al, ESC Scientific Document Group, 2019 ESC/EAS Guidelines for the management of dyslipidemias: lipid modification to reduce cardiovascular risk: The Task Force for the management of dyslipidemias of the European Society of Cardiology (ESC) and European Atherosclerosis Society (EAS). European Heart Journal, ehz 455, https://doi.org/10.1093/eurheartj/ehz455

2. Hughes S. New European lipid guidelines take aggressive approach. Medscape Medical News. September 1, 2019. Available at: https://www.medscape.com/viewarticle/917551. Accessed October 3, 2019.

3. Wilkins E, Wilson L, Wickramasinghe K, et al. European Cardiovascular Disease Statistics 2017. European Heart Network, Brussels. Available at: http://www.ehnheart.org/ images/CVD-statistics-report-August-2017.pdf

4. Piepoli MF, Hoes AW, Agewall S, Brotons C. 2016 European Guidelines on cardiovascular disease prevention in clinical practice: The Sixth Joint Task Force of the European Society of Cardiology and Other Societies on Cardiovascular Disease Prevention in Clinical Practice developed with the special contribution of the European Association for Cardiovascular Prevention \& Rehabilitation (EACPR). Eur Heart J. 2016;37(29):2315-2381.

5. Lin JS, Evans CV, Johnson E, et al. Nontraditional risk factors in cardiovascular disease risk assessment: updated evidence report and systematic review for the US Preventive Services Task Force. JAMA. 2018;320(3):281-297.

6. Cho I, Al'Aref SJ, Berger A, et al. Prognostic value of coronary computed tomographic angiography findings in asymptomatic individuals: a 6-year follow-up from the prospective multicentre international CONFIRM study. Eur Heart J, 2018;39(11):934-941.

7. Nordestgaard BG, Langsted A. Lipoprotein (a) as a cause of cardiovascular disease: insights from epidemiology, genetics, and biology. J Lipid Res, 2016;57(11):1953-1975.

8. Parish S., Hopewell JC, Hill MR, et al. Impact of apolipoprotein(a) isoform size on lipoprotein(a) 
lowering in the HPS2-THRIVE study. Circ Genom Precis Med. 2018;11(2):e001696.

9. Ray KK, Vallejo-Vaz AJ, Gisberg HN. Lipoprotein(a) reductions from PCSK9 inhibition and major adverse cardiovascular events: Pooled analysis of alirocumab phase 3 trials. Atherosclerosis, 2019;288: 194-202.

10. El Andere T, Soto JAT, Moreira IS. Are we being able to meet current guidelines LDL-cholesterol goals in very high-risk patients? How many of them could benefit of PSCK9 inhibition by the FOURIER/ODYSSEY and NICE criteria? European Heart Journal, 2019;40(Supplement 1):ehz746.0296.

11. Mulverstedt S, Klausen IC, Kanstrup H. Treatment of hypercholesterolemia with PCSK9 inhibitors in Denmark. Assessment of real-life data; Extent and Efficacy after the first years of clinical use. European Heart Journal, 2019;40(Supplement 1):ehz745.0002.

12. Cannon CP, Blazing MA, Giugliano RP. Ezetimibe added to statin therapy after acute coronary syndromes. N Engl J Med. 2015;372(25):2387-97.

13. Bhatt DL, Steg G, Brinton EA. Rationale and design of REDUCE-IT: Reduction of Cardiovascular Events with Icosapent Ethyl-Intervention Trial. Clin Cardiol. 2017;40(3): $138-148$.
14. Mason RP. New insights into mechanisms of action for omega-3 fatty acids in atherothrombotic cardiovascular disease. Curr Atheroscler Rep 2019; 21(1): 2.

15. Chapman MJ, Redfern JS, McGovern ME. Niacin and fibrates in atherogenic dyslipidemia: pharmacotherapy to reduce cardiovascular risk. Pharmacol Ter. 2010;126(3):314-45.

16. Accord Study Group, Ginsberg HN, Elam MB, Lovato LC, Crouse JR III, Leiter LA, Linz P. Effects of combination lipid therapy in type 2 diabetes mellitus. $N$ Engl J Med 2010;362(17):1563-74.

17. Keech A, Simes RJ, Barter P, et al, FIELD study investigators. Effects of long-term fenofibrate therapy on cardiovascular events in 9795 people with type 2 diabetes mellitus (the FIELD study): randomized controlled trial. Lancet 2005;366(9500):1849-61.

18. Catapano AL, Farnier M, Foody JM. Combination therapy in dyslipidemia: where are we now? Atherosclerosis 2014;237(1):319-35.

19. Cholesterol Treatment Trialists' Collaboration. Efficacy and safety of statin therapy in older people: a meta-analysis of individual participant data from 28 randomized controlled trials. Lancet 2019;393:407-15.

20. Karalis DG, Hill AN, Clifton S, Wild RA. The risks of statin use in pregnancy: a systematic review. J Clin Lipidiol. 2016;10(5):1081-90. 